\title{
Ensinar Química com Telemóveis INTELIGENTES: a Tabela Periódica em Código QR
}

VASCO D.B. BONIFÁCIO*

\begin{abstract}
ensino moderno não pode ficar indiferente ao ambiente tecnológico atual. 0 recurso a conteúdos educativos online por parte de professores e alunos tem vindo a generalizar-se e constitui sem dúvida um excelente complemento da atividade letiva. Neste contexto, o ensino de Química, em especial o ensino da Tabela Periódica dos Elementos (TP), constitui um desafio, dada a sua complexidade. A TP áudio codificada em código QR é uma nova ferramenta que permite ensinar os elementos químicos de forma atrativa usando um telemóvel inteligente. 0 ensino de conteúdos de Química em registo áudio é por outro lado uma mais valia para alunos invisuais ou amblíopes, evitando o recurso ao braille.
\end{abstract}

A Tabela Periódica dos Elementos (TP) é um dos ícones mais fascinantes da Química. Foi criada por Dimitri Mendeleev em 1869, e desde essa data já foram publicadas mais de 700 versões [1]. Apesar de ter sido elaborada há quase 150 anos, a TP ainda não está totalmente completa, havendo ainda alguma controvérsia no reconhecimento da descoberta de alguns elementos. Muito recentemente, e após um período de três anos de revisão científica, uma comissão da IUPAC (International Union of Pure and Applied Chemistry) reconheceu oficialmente a descoberta de mais dois elementos $(Z=114$ e $Z=116)$ [2]. Atualmente, a TP pode ser encontrada em diversos formatos, desde o clássico poster em papel, até ás versões digitais, dinâmicas e interativas [3]. Contudo, a informação química acessível a estudantes invisuais ou amblíopes é ainda escassa, sendo de destacar alguns esforços que vêm sendo feitos em Portugal pelo ECEGAM (grupo de trabalho para o ensino de cegos e grandes amblíopes) [4], em parceria com a ACAPO (Associação de Cegos e Amblíopes de Portugal), que desenvolveu já um software que permite a um invisual desenhar e navegar através de estruturas químicas [5]. Por esta razão, o desenvolvimento de ferramentas, especialmente em formato áudio, que tornem a química acessível a todos, é urgente e crucial. Os materiais em formato áudio aceleram de forma extraordinária

*REQUIMTE, Departamento de Química, Faculdade de Ciências e Tecnologia, Universidade Nova de Lisboa, 2829-516 Caparica

Email: vbb@fct.unl.pt o processo de aprendizagem do aluno invisual, evitando o recurso ao Braille. Os telefones inteligentes (smart phones, ex. iPhone, Android e Blackberry) e os tablets (ex. iPad) são cada vez mais uma ferramenta do dia a dia, cujo potencial é muitas vezes desconhecido pelos próprios utilizadores. $\mathrm{O}$ uso de telefones inteligentes no ensino da química na sala de aula tem vindo a crescer, em especial nos Estados Unidos [6], e irá em breve alterar de forma radical as atuais metodologias de ensino. Um grupo de investigadores da Universidade de Nottingham concluiu recentemente o projeto da TP em vídeo [7]. Cada elemento químico possui um vídeo associado que se encontra publicado no Youtube. Usando códigos Quick-Response (QR) foi depois construída uma TP vídeo (QR-TPV) [8]. Os códigos QR são códigos de barras 2D que foram desenvolvidos no Japão em 1994 pela empresa Denso Ware. Embora estando patenteados, o seu uso é totalmente livre pois a empresa decidiu não exercer os seus direitos de patente. Os códigos QR são lidos usando um telefone inteligente/tablet através de uma aplicação (gratuita) adequada
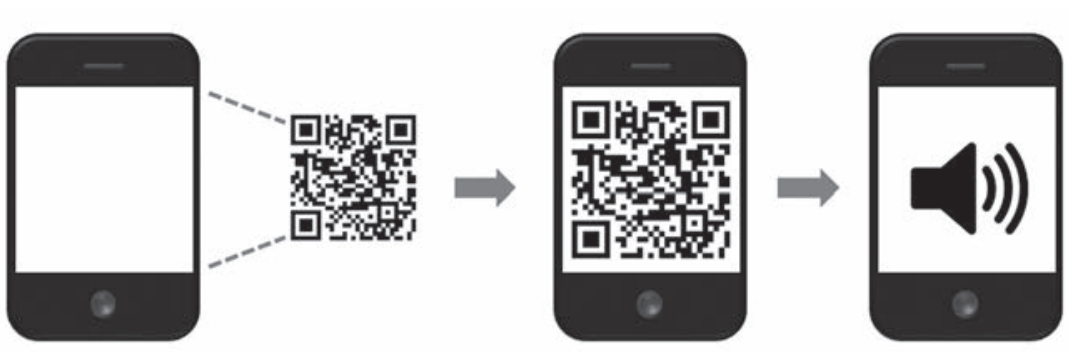

Figura 1 - Esquema de leitura de um código QR, contendo uma mensagem áudio, usando um telemóvel inteligente

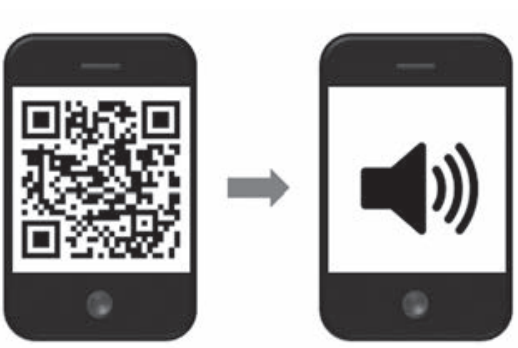

ao fabricante (ex. para iPhone/iPad usa-se a aplicação i-nigma obtida na loja online da Apple). Um código QR é gerado online de forma automática [9] e a informação que pode armazenar é escolhida pelo utilizador. Pode ser um pequeno texto, um link para uma página na internet, as coordenadas de um mapa do Google ou uma mensagem de voz [10]. A informação que escolhermos irá aparecer no ecrã do telefone inteligente após a leitura do código QR (Figura 1).

Embora a QR-TPV seja bastante útil, possui muita informação visual que é perdida se for usada por um aluno cego ou amblíope. Por esta razão foi desenvolvida uma versão áudio da TP codificada em código QR (QR-TPA) que é acessível a todos [11]. A QR-TPA pode ser descarregada livremente da internet [12]. A Figura 2 mostra a QR-TPA e sua leitura usando um telemóvel inteligente.

Esta nova versão da TP foi construída com base numa versão áudio existente em língua inglesa que se encontra disponível online no website "Chemistry in its Element", da Royal 
Society of Chemistry [13]. A versão portuguesa da QR-TPA encontra-se neste momento em desenvolvimento. Em Portugal, o uso da QR-TPA na sala de aula poderá ser facilmente integrado nos programas curriculares de Física e Química (10. ${ }^{\circ}$ ano) e de Química (12. ${ }^{\circ}$ ano), incluindo ou não alunos invisuais. A QR-TPA poderá ajudar os alunos a envolver-se na temática da TP de uma forma divertida, usando uma ferramenta muito atrativa, permitindo uma exploração individual (com recurso a auriculares) ou coletiva. Esta exploração poderá mesmo estender-se a outros locais fora da sala de aula (ex. transportes públicos), potenciando a aquisição de conhecimentos por parte do aluno. $\mathrm{Na}$ versão impressa destinada a alunos invisuais, os símbolos químicos dos elementos deverão ser previamente rotulados em Braille e colados na QR-TPA. O aluno invisual deverá também aprender qual a distância ótima para ler o código QR a partir da TP, de modo a poder realizar uma aprendizagem autónoma quando o ensino não estiver a ser tutorado. Após a leitura do código QR, o telemóvel inteligente emite um sinal sonoro e a descrição áudio inicia-se automaticamente (é necessária uma ligação Wi-Fi à internet no local da leitura). O uso da QR-TPA não está condicionado ao suporte em papel, podendo a leitura do código QR ser igualmente realizada a partir de écrans de computador ou de projeção.

Em resumo, o ensino de química usando telemóveis inteligentes/tablets apresenta-se como uma nova metodologia de ensino para todos os alunos, em especial cegos e amblíopes. Num futuro próximo é esperado que o mobile-learning seja adotado em Portugal para todos os níveis de ensino.

A demonstração do uso da QR-TPA está documentada na entrevista que o autor do artigo deu ao programa "Com Ciência" transmitido pela RTP 2 [14].

\section{AgradeCIMENTOS}

Fundação para a Ciência e a Tecnologia e FEDER (Projeto CHEM4ALL: RIPD/APD/109547/2009). QRandGO ${ }^{\circledR}$ pelo suporte técnico na elaboração da QR-TPA.

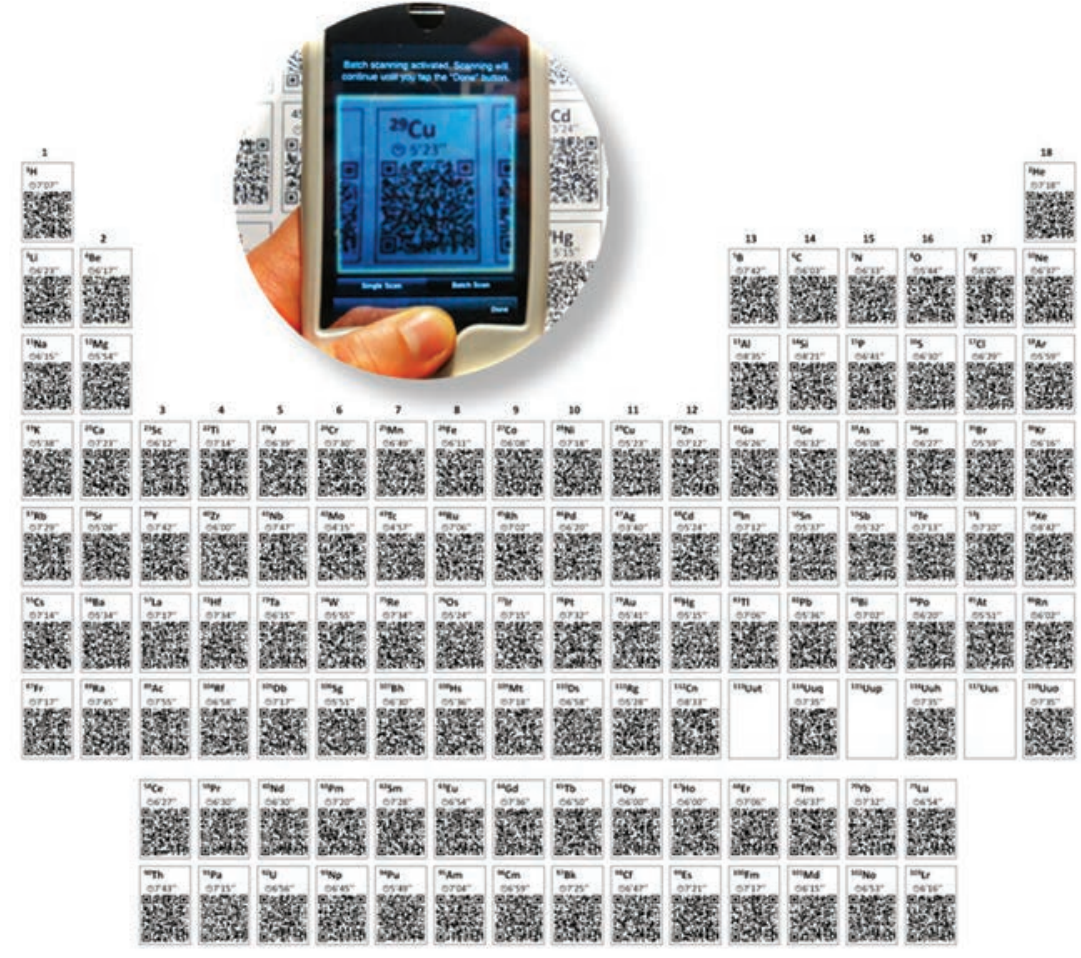

Figura 2 - Leitura da QR-TPA usando um telemóvel inteligente
NotA

Este artigo também está disponível em versão html no site da Sociedade Portuguesa de Química (http://www.spq.pt/ QUIMICA/multimedia), onde os leitores poderão aceder diretamente às referências e recursos mencionados.

\section{REFERÊNCIAS}

[1] E.R. Scerri, The Periodic Table: Its Story and Its Significance, Oxford University Press, New York, 2007.

[2] R.C Barber, P.J. Karol, H. Nakahara, E. Vardaci, E.W. Vogt, Pure Appl. Chem. 83 (2011) 1485-1498.

[3] M. Dayah, Dynamic Periodic Table: http://www.ptable.com (acedido em 01-01-2012).

[4] Website do ECEGAM: http://bit.ly/ ECEGAM (acedido em 01-01-2012).

[5] F. Pereira, J. Aires-de-Sousa, V.D.B. Bonifácio, P. Mata, A.M. Lobo, J. Chem. Educ. 88 (2011) 361-362.

[6] A.J. Williams, H.E. Pence, J. Chem. Educ. 88 (2011) 683-686.

[7] Tabela Periódica em Vídeos: http:// www.periodicvideos.com (acedido em 01-01-2012).

[8] Tabela Periódica QR em Vídeo: http://bit.ly/videoPTE (acedido em 01-01-2012).

[9] Exemplo de geradores online de códigos QR: (a) http://zxing.appspot. com/generator (b) http://qrcode.kaywa.com (acedidos em 01-01-2012).

[10] Website que permite traduzir uma mensagem de texto numa mensagem de voz através de um código QR: http://qrvoice.net (acedido em 01-01-2012).

[11] V.D.B. Bonifácio, J. Chem. Educ. 89 (2012) 552-554.

[12] Poster da QR-TPA: http://bit.ly/QRTPA (acedido em 01-01-2012).

[13] Website da TPE áudio da Royal Society of Chemistry: http://www. rsc.org/chemistryworld/podcast/element.asp (acedido em 01-01-2012)

[14] Entrevista do autor do artigo ao programa "Com Ciência" (RTP 2): http:// bit.ly/ComCienciaQR-TPA (acedido em 01-01-2012).

\section{Sociedade Portuguesa de Química}

Av. da República, 45 - 3Esq. - 1050-187 Lisboa * Tel.: 217934637 * Fax: 217952349 * e-mail: sede@spq.pt Horário: 9:45 às $13: 00$ e das $14: 30$ às $18: 00$ 